Robert Dittmar is a mathematician and William T. Gavin is vice president and research coordinator for the Federal Reserve Bank of St. Louis. Finn E. Kydland is a professor of economics at Carnegie Mellon University and visiting scholar of the Federal Reserve Bank of St. Louis. Daniel R. Steiner provided research assistance.

\section{The Inflation- Output Variability Tradeoff and Price-Level Targets}

\author{
Robert Dittmar, William T. \\ Gavin, and Finn E. \\ Kydland
}

T he stated long-term goal of monetary policy in the United States and around the world is price stability. Eight countries in the world now have explicit targets for inflation. Many more, including the United States, appear to operate as if they have implicit targets for inflation. There is an ongoing debate about how strictly one should try to target inflation. The idea is that if one tried to keep inflation too close to a target, there would be a significant increase in the variability of output and interest rates.

There is a subtle but important distinction to be made about the difference between targeting inflation in the short run (say, every month) and targeting a particular average inflation rate over many months. By targeting a long-moving average of zero inflation, or a horizontal price-level path, the central bank would have an operational target for price stability, but would not be required to keep inflation on an exact path each month or quarter. Objections to price-level targeting usually assume that any economic disturbance that caused the price level to deviate from the target would require the central bank to react immediately, and harshly, to get the price level back on track. But, there is no reason for this. Whether targeting inflation more closely in the long-run would lead to more or less short-run variability of inflation and output depends on how the economy works and how the central bank runs monetary policy.

By price-level targeting we mean that the central bank announces a path for the price level. It may beflat or it may be changing at a rate of $\mathrm{x}$ percent per year. For $\mathrm{x}=0$, the price level path will be horizontal. In any case, the notion of a price-level target means that the central bank will target a long-run average inflation rate, setting objectives that correct for past deviations from the target. Technically, we define a pricelevel-targeting regime as one in which the logarithm of the price level has a deterministic trend. An inflation-targeting regime is one in which the logarithm of the price level has a unit root and follows a stochastic trend. Results in this paper apply to a price-level target whether the average inflation rate is zero or not.

Taylor (1979) introduced the idea of using the inflation/output variability tradeoff to examine alternative monetary policy rules. Using a rational expectations model with staggered wage contracts, he explained why the choice facing policymakers in a dynamic setting involves the tradeoff between output variability and inflation variability. In his rational expectations framework there is no long-run tradeoff between levels of output and inflation. Policymakers can, however, choose alternative points along an inflation/ output variability frontier by varying the relative weight they put on inflation versus output stabilization. ${ }^{1}$

Using a simplified version of Taylor's framework, Svensson (1997b) shows that, for a given level of output variability, the short-run variability of inflation depends on the amount of persistence in the output gap and on whether the central bank targets an inflation rate or a path for a price index. He shows that if the output gap is persistent enough, the central bank should target a

\footnotetext{
${ }^{1}$ For a more detailed description of the intuition underlying the inflation/ output variability tradeoff, see Taylor (1994).
} 
path for the price level. Svensson also explains why a price-level target can be used as a commitment mechanism to eliminate the inflation bias that results when a central bank tries to target an unrealistically high level of output. ${ }^{2}$ In this paper, we explain how the inflation-output variability tradeoff changes if the central bank chooses to target a predetermined path for the price level rather than an inflation rate. Our analysis is more transparent than Svensson's because we do not try to distinguish between cases of commitment and discretion, nor do we consider the case where the central bank tries to achieve an unrealistic objective for output. We assume that the central bank cannot commit credibly to more than one period at a time. Since the central bank does not try to achieve unrealistically high levels of output, the steady state inflation rates are the same for both inflation and price-level targeting regimes.

\section{INFLATION VERSUS PRICE-LEVEL TARGETING IN A SIMPLE PHILLIPS CURVE MODEL}

The basic model described here is from Svensson (1997a, 1997b). The model is consistent with a wide range of sticky-price models in which monetary policy can have important real effects. The model has three main elements: a multiperiod objective function for the central bank, an aggregate supply equation, and a rational expectations assumption.

The central bank minimizes an intertemporal quadratic loss function:

\footnotetext{
2 Gavin and Stockman (1991) explain why a society that cares about inflation (not price level) stability may still prefer a price level target if the source of inflation shocks is unobservable to the public.

${ }^{3}$ An appendix in Svensson (1997b) shows that introducing money with a control error in the inflation equation would not change his results.
}

parameter, $\lambda$, relates the central bank's preference for output stability to its preference for inflation stability.

The economy is modeled as a shortrun aggregate supply curve with persistence in the output gap:

$$
\mathrm{y}_{\mathrm{t}}=\rho \mathrm{y}_{\mathrm{t}-1}+\alpha\left(\pi_{\mathrm{t}}-\pi_{\mathrm{t}}^{\mathrm{e}}\right)+\varepsilon_{\mathrm{t}} .
$$

The introduction of a lagged output gap in this equation is important for comparing inflation and price-level targeting. Conceptually, the lag will be introduced any time friction prevents instantaneous and complete adjustment of output to unexpected changes in the price level. This friction could be induced by wage contracts, menu costs, transaction costs, incomplete markets, capital adjustment costs, etc. The slope of the short-run Phillips Curve is given by $\alpha$ which determines the response of the output gap to unexpected inflation $\left(\pi_{\mathrm{t}}-\pi_{\mathrm{t}}^{\mathrm{e}}\right)$.

With this aggregate supply curve and rational expectations, that is, $\pi_{\mathrm{t}}^{\mathrm{e}}=\mathrm{E}_{\mathrm{t}-1} \pi_{\mathrm{t}}$, the central bank's optimization problem implies a tradeoff between output and inflation variability. Minimizing this loss functionsubject to the aggregate supply curve- leads to a rule for inflation that is contingent on the size of the output gap:

$$
\begin{aligned}
& \pi_{\mathrm{t}}^{\mathrm{A}}=\mathrm{p}_{\mathrm{t}}^{\mathrm{A}}-\mathrm{p}_{\mathrm{t}-1}=\pi^{*}-\frac{\alpha \lambda \rho}{1-\beta \rho^{2}} \mathrm{y}_{\mathrm{t}-1} \\
& -\frac{\alpha \lambda}{1-\beta \rho^{2}+\alpha^{2} \lambda} \varepsilon_{\mathrm{t}}
\end{aligned}
$$

where the superscript $A$ indicates that the variable is determined by the inflation-targeting rule and $p$ is the logarithm of the price level. The inflation rate set in each period is equal to the inflation target with countercyclical adjustments proportional to the lagged output gap and the current technology shock. Following Svensson, we assume the central bank can control inflation directly. ${ }^{3}$ Details of the solution procedure are presented in the appendix.

If the central bank cares about deviations of the price level rather than the 
inflation rate, the natural logarithm of the price level will replace the inflation rate in the loss function. We reformulate the objective function as below:

$$
L=\sum_{t=0}^{\infty} \beta^{t}\left(\lambda y_{t}^{2}+\left(p_{t}-p_{t}^{*}\right)^{2}\right),
$$

where the target path for the price level may be constant or may be rising at a constant rate.

The central bank's rule for achieving the target path is given by:

$$
\begin{array}{r}
\mathrm{p}_{\mathrm{t}}^{\mathrm{B}}=\mathrm{p}_{\mathrm{t}}^{*}-\frac{\alpha \lambda \rho}{1-\beta \rho^{2}} \mathrm{y}_{\mathrm{t}-1} \\
-\frac{\alpha \lambda}{1-\beta \rho^{2}+\alpha^{2} \lambda} \varepsilon_{\mathrm{t}},
\end{array}
$$

implying the following rule for the inflation rate:

$$
\begin{aligned}
\pi_{\mathrm{t}}^{\mathrm{B}} & =\mathrm{p}_{\mathrm{t}}^{\mathrm{B}}-\mathrm{p}_{\mathrm{t}-1}=\pi^{*} \\
& -\frac{\alpha \lambda \rho}{1-\beta \rho^{2}}\left(\mathrm{y}_{\mathrm{t}-1}-\mathrm{y}_{\mathrm{t}-2}\right) \\
& -\frac{\alpha \lambda}{1-\beta \rho^{2}+\alpha^{2} \lambda}\left(\varepsilon_{\mathrm{t}}-\varepsilon_{\mathrm{t}-1}\right),
\end{aligned}
$$

where we have used the assumption that the price-level target, $p_{t}^{*}$, is given by $p_{\mathrm{t}}^{*}=\pi^{*}+p_{\mathrm{t}-1}{ }^{*}$. The superscript $\mathrm{B}$ indicates that the variable is determined by the price-level targeting rule. With the pricelevel target, the central bank's reaction function, Equation 6, has three elements on the right-hand side. The first is the steadystate inflation embodied in the target path for the price level. The second and third are proportional, countercyclical adjustments to the change in the output gap from period $t-2$ to period $t-1$ and the change in the technology shock from period $\mathrm{t}-1$ to period $t$, respectively.

The tradeoff between inflation and output is qualitatively different under the two different regimes, inflation targeting and price-level targeting. In an inflationtargeting regime, the bank sets inflation, $\pi_{\mathrm{t}}^{\mathrm{A}}$, as shown in Equation 3. With rational expectations, the model's Phillips Curve implies that output is given by:

$$
\mathrm{y}_{\mathrm{t}}=\rho \mathrm{y}_{\mathrm{t}-1}+\frac{1-\beta \rho^{2}}{1-\beta \rho^{2}+\alpha^{2} \lambda} \varepsilon_{\mathrm{t}} \text {. }
$$

As the relative weight on output variability, $\lambda$, gets large, the coefficient on the error term tends to zero as does the variance of the output gap. If the variance of $\varepsilon_{\mathrm{t}}$ is $\sigma_{\varepsilon}^{2}$, then the above decision rule for $y_{t}$ implies that the unconditional variance of the output gap is:

$$
\sigma_{y}^{2}=\frac{\left(1-\beta \rho^{2}\right)^{2}}{\left(1-\rho^{2}\right)\left(1-\beta \rho^{2}+\alpha^{2} \lambda\right)^{2}} \sigma_{\varepsilon}^{2}
$$

After noting that $\varepsilon_{\mathrm{t}}$ is uncorrelated with $\mathrm{y}_{\mathrm{t}-1}$, we can use the decision rule for $\pi_{\text {t }}$ to calculate the unconditional variance of inflation as:

$$
\begin{aligned}
\sigma_{\pi}^{2} & =\left(\frac{\alpha \lambda \rho}{1-\beta \rho^{2}}\right)^{2} \sigma_{y}^{2} \\
& +\left(\frac{\alpha \lambda}{\left(1-\beta \rho^{2}+\alpha^{2} \lambda\right)}\right)^{2} \sigma_{\varepsilon}^{2},
\end{aligned}
$$

which can be simplified to yield an expression only involving $\sigma_{\varepsilon}^{2}$, namely:

$$
\sigma_{\pi}^{2}=\frac{\alpha^{2} \lambda^{2}}{\left(1-\rho^{2}\right)\left(1-\beta \rho^{2}+\alpha^{2} \lambda\right)^{2}} \sigma_{\varepsilon}^{2}
$$

In a price-level-targeting regime, the central bank sets the inflation rate, $\pi_{\mathrm{t}}^{\mathrm{B}}$, as in Equation 5. Once again assuming rational expectations, $p_{t}^{e}=E_{t-1} p_{t}$, the following time series process for the output gap is derived from the model's Phillips Curve,

$$
\mathrm{y}_{\mathrm{t}}=\rho \mathrm{y}_{\mathrm{t}-1}+\frac{1-\beta \rho^{2}}{1-\beta \rho^{2}+\alpha^{2} \lambda} \varepsilon_{\mathrm{t}} .
$$

Note that this process for the output gap looks identical to Equation 7, which was derived in the inflation-targeting regime. The parameter $\lambda$, how ever, has a different 


\section{Figure 1}

The Output-Inflation Variability Tradeoff

Variability of the Output Gap

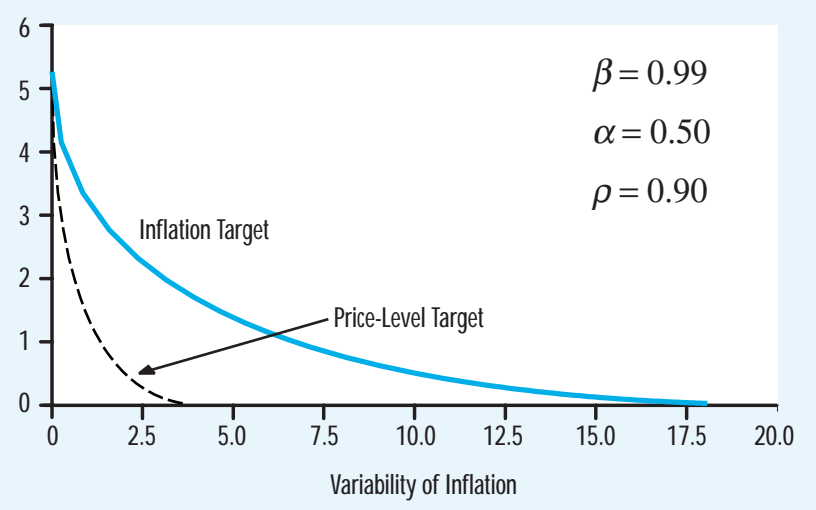

interpretation here, as the bank's preferences are different. The unconditional variance of the output gap as a function of this parameter is given by the same expression as noted in Equation 8. The unconditional variance of the inflation rate, however, is given by the following expression:

$$
\sigma_{\pi}^{2}=\frac{2 \alpha^{2} \lambda^{2}}{(1+\rho)\left(1-\beta \rho^{2}+\alpha^{2} \lambda\right)^{2}} \sigma_{\varepsilon}^{2}
$$

Regardless of whether the central bank is targeting inflation or the price level, a small weight on the output gap leads the bank to strive for keeping inflation or the price level close to its target. At the extreme, where the central bank places no weight on deviations of the output gap, the variance of the gap is determined by persistence in the output gap, $\rho$, and the variance of technology shocks. Here, the bank optimizes by fixing inflation, or the price level, at its target in every period. There is no inflation variability, no inflation uncertainty, and a simple autoregressive process for the output gap. Conversely, a large weight on the deviation of the output gap from the target would lead the bank to use the Phillips Curve constraint to closely control the output gap by letting inflation vary more.

We graphically display the difference between the inflation/output variability trade- offs in the two regimes by first expressing the output gap variance and the inflation variance as functions of the preference parameter $\lambda$ while holding the parameters of the Phillips Curve constant. For a given $\lambda$, the bank's decision rules can be used to calculate an unconditional variance for both inflation and the output gap (a single point in Figure 1). Varying the bank's preferences by varying $\lambda$ will determine the location of the curve representing the trade off between $\sigma_{\pi}^{2}$ and $\sigma_{\mathrm{y}}^{2}$.

A sample pair of variance tradeoff curves are displayed in Figure 1. For the chosen set of parameter values, the variance tradeoff under the price-level-targeting regime lies everywhere below that for the inflation-targeting regime. Thus, given this particular set of parameters, society would prefer the price-level-targeting regime.

More can be said about the relative position of these tradeoff curves. If we examine the expressions for the unconditional variances of the output gap and inflation derived above, we can fully describe the position of these curves in terms of the autoregressive parameter, $\rho$, in the Phillips Curve equation. Note that in either regime, if the bank places no weight on deviations of the output gap from target, then the bank simply sets the inflation rate, or the price level, equal to its target in every period. Thus, in the limit as the parameter $\lambda$ approaches 0 , the unconditional variance of inflation approaches 0 , while the unconditional variance of output approaches that of the simple first-order autoregressive process $\mathrm{y}_{\mathrm{t}}=\rho \mathrm{y}_{\mathrm{t}-1}+\varepsilon_{\mathrm{t}}$. Thus, the two tradeoff curves intersect the $\sigma_{y}^{2}$-axis at the same point.

If the central bank's weight on deviations of the output gap from target becomes large, then the central bank sets the output gap equal to its target and manipulates the inflation rate to reach this goal. Thus, as the parameter $\lambda$ approaches infinity, the variance of output approaches 0 . Examining the expressions for the unconditional variance of inflation shows that as $\lambda$ approaches infinity, the variance of inflation under an inflationtargeting regime approaches $\left(\alpha^{2}\left(1-\rho^{2}\right)\right)^{-1}$, and the variance of inflation under a pricelevel-targeting regime approaches 
$2\left(\alpha^{2}(1+\rho)\right)^{-1}$. Therefore, assuming that the tradeoff curves are convex for all parameter values, the tradeoff curves under pricelevel-targeting regimes will lie below those for inflation-targeting regimes as long as

$$
2\left(\alpha^{2}(1+\rho)\right)^{-1}<\left(\alpha^{2}\left(1-\rho^{2}\right)\right)^{-1},
$$

or equivalently, $\rho>1 / 2 .{ }^{4} \mathrm{~N}$ ote that the relative position of the tradeoff curves does not depend on $\alpha$, the slope of the shortrun Phillips Curve, or on $\beta$, the central bank's discount factor.

We can gain some insight for the relative placement of the curves under the above condition by considering what happens as the auto-regressive parameter, $\rho$, approaches 1 . As this happens, the output gap starts to behave more and more like a random walk. Under the inflation-targeting regime, the bank sets the inflation rate proportional to the output gap. Consequently, if the output gap behaves like a random walk, so will the inflation rate. Under the price-leveltargeting regime, however, the bank sets the inflation rate proportional to the change in the output gap. Thus, even if the output gap becomes non-stationary as $\rho$ approaches 1 , the time path of the inflation rate remains stationary under such a regime.

\section{EMPIRICAL EVIDENCE}

The simple Phillips Curve model represents popular wisdom about the tradeoff between inflation and output variability. It is instructive to examine estimates of the persistence in the output gap. We use U.S. gross domestic product (GDP) data where we calculate three different measures of the output gap from three different measures of potential GDP:

- Congressional Budget Office (CBO) estimates.

- A quadratic time (QT) trend calculated using the logarithm of real GDP.

- A Hodrick-Prescott (HP) trend also calculated using logarithm real GDP.

\section{Table 1}

Output Gap Under Alternate Definitions of Trend GDP

\begin{tabular}{|c|c|c|c|}
\hline & CBO & $\begin{array}{l}\text { Quadratic } \\
\text { Time }\end{array}$ & $\begin{array}{l}\text { Hodrick- } \\
\text { Prescott }\end{array}$ \\
\hline CBO & $2.7 \%$ & & \\
\hline Quadratic Time & 0.84 & $3.1 \%$ & \\
\hline Hodrick-Prescott & 0.79 & 0.76 & $1.7 \%$ \\
\hline
\end{tabular}

Values on the diagonal are the standard deviations of the output gap variously measured. Values on off-diagonals are the correlation coefficients between the respective measures of the output gap. Data are quarterly U.S. GDP from 1949:Q1 to 1998:Q2. The quadratic time gap is calculated as the residual in the following regression:

$$
\mathrm{y}_{\mathrm{t}}=\text { constant }+\hat{\beta}_{1} \text { Time }+\hat{\beta}_{2} \mathrm{Time}^{2}+\hat{\mathrm{e}}_{\mathrm{t}}
$$

where yt is the logarithm of GDP and $\hat{\mathrm{e}}$ is the estimated residual. The Hodrick-Prescott gap is the deviation from trend calculated using the filter described in Prescott (1986).

\section{Table 2}

Estimates of Persistence in the Output Gap Using U.S. GDP Data

$$
\Delta \mathrm{y}_{\mathrm{t}}=\mathrm{c}+\rho \mathrm{y}_{\mathrm{t}-1}+\sum \omega_{\mathrm{i}} \Delta \mathrm{y}_{\mathrm{t}-\mathrm{i}}+\mathrm{e}_{\mathrm{t}}
$$

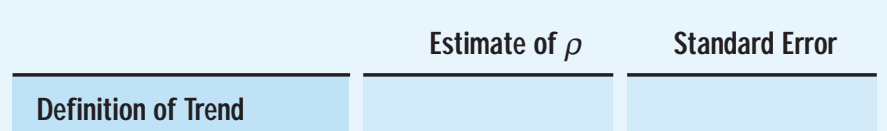

\begin{tabular}{l|l|l|}
\hline CBO & 0.91 & 0.03 \\
\hline Quadratic Time & 0.92 & 0.03 \\
\hline Hodrick-Prescott & 0.79 & 0.05 \\
\hline
\end{tabular}

Data are quarterly U.S. GDP from 1949:Q1 to 1998:Q2.

In each case, we calculate the output gap as the difference between the logarithm of real GDP and the alternate estimates of the trend. Table 1 shows the sample standard deviations and correlations between the different measures of the output gap. The estimate based on the quadratic time trend is the most variable and the most highly correlated with the CBO estimate. We assume the CBO estimate is closest to the data that the policymakers actually use.

Table 2 shows the estimates of the autoregressive parameter calculated for each measure of the output gap. The

\footnotetext{
${ }^{4}$ Svensson (1997b) derived a similar result for the discretion case.
} 


\section{Table 3}

\section{Estimates of Persistence in the Output Gap}

(Using industrial Production to Measure Output)

$$
\Delta \mathrm{y}_{\mathrm{t}}=\mathrm{c}+\rho \mathrm{y}_{\mathrm{t}-1}+\sum \omega_{\mathrm{i}} \Delta \mathrm{y}_{\mathrm{t}-\mathrm{i}}+\mathrm{e}_{\mathrm{t}}
$$

\begin{tabular}{|c|c|c|c|c|}
\hline Country & Hodric & tt Filter & Quadrati & end Filter \\
\hline & Estimate of $\rho$ & Standard Error & Estimate of $\rho$ & Standard Error \\
\hline Belgium & 0.58 & 0.08 & 0.90 & 0.04 \\
\hline Canada & 0.77 & 0.05 & 0.94 & 0.02 \\
\hline France & 0.41 & 0.10 & 0.89 & 0.05 \\
\hline Germany & 0.69 & 0.06 & 0.93 & 0.03 \\
\hline Italy & 0.53 & 0.09 & 0.90 & 0.04 \\
\hline Japan & 0.82 & 0.04 & 0.97 & 0.01 \\
\hline Netherlands & 0.51 & 0.09 & 0.97 & 0.02 \\
\hline Sw eden & 0.57 & 0.07 & 0.96 & 0.02 \\
\hline United Kingdom & 0.60 & 0.07 & 0.89 & 0.04 \\
\hline United States & 0.70 & 0.05 & 0.93 & 0.03 \\
\hline
\end{tabular}

Data for the G-10 are quarterly averages of monthly industrial production from 1957:1 to 1997:12 published by the International Monetary Fund.

equation used to estimate $\rho$ is shown at the top of Table 2. The properties of the distribution for this estimate were discussed in Dickey and Fuller (1981). By construction, the output gap is stationary so there is no prior reason to expect estimates of $\rho$ to be close to unity. We find surprisingly high estimates of $\rho$ using both the QT gap (0.92) and the CBO gap (0.91), however. The HP trend follows the actual series more closely than the other two series. The standard deviation is much smaller and the estimate of $\rho$ is only 0.72 . Even in this case, however, the estimate is still more than four standard deviations larger than 0.50 . This confirms Svensson's result that if one believes in this output/inflation variability tradeoff, then setting a price-level target would most likely result in a more efficient set of options for the Fed than would an inflation target.
We also have estimated the persistence of the output gap in the G-10 countries. There is a lack of historical quarterly GDP data for the G-10, so we measured the persistence of the output gap in these countries by taking quarterly averages of industrial production and using both the HP and QT filters (see Table 3 ) to construct the output gap. Using the QT filter, $\rho$ is estimated to be greater than 0.50 and highly significant in all the countries. Using the HP filter, the results are mixed. Only in one case is the point estimate below 0.50 , but in over half of the cases, the estimate is within one standard deviation of 0.50 .

\section{CONCLUSION}

In this paper we describe a popular model of monetary policy in which the central bank minimizes a discounted, multiperiod loss function that includes deviations of infla- 
tion and output from target levels. This minimization is constrained by a short-run tradeoff between inflation and real output. This simple model suggests that the choice between an inflation target and a pricelevel target depends on characteristics of real output. If the output gap is relatively persistent, then targeting the price level results in a better set of policy options for the central bank. We present evidence from the G-10 countries showing that conventionally measured output gaps are highly persistent. The policy implication of assuming rational expectations and this Phillips Curve model is that central banks should set objectives for a price level, not an inflation rate.

\section{REFERENCES}

Dickey, David A. and Wayne A. Fuller. "Likelihood Ratio Statistics for Autoregressive Time Series with a Unit Root," Econometrica 49 (June 1981), pp. 1057-72.

Gavin, William T., and Alan Stockman. "Why a Rule for Stable Prices May Dominate a Rule for Zero Inflation," Economic Review, Federal Reserve Bank of Cleveland, (1991 Quarter I), pp. 2-8.

Hodrick, Robert I., and Edward C. Prescott. "Postwar U.S. Business Cycles: An Empirical Investigation," Joumal of Money, Credit, and Banking, 29 (February 1997), pp. 1-16.

Prescott, Edward C. "Theory Ahead of Business Cycle Measurement," Carnegie-Rochester Conference Series on Public Policy. New York: North-Holland, (Autumn1986).

Svensson, Lars E.O. "Optimal Inflation Targets, 'Conservative' Central Banks, and Linear Inflation Contracts," American Economic Review 87 (March 1997a), pp. 98-114.

. "Price Level Targeting vs. Inflation Targeting: A Free Lunch?" Institute for Intemational Economic Studies, Stockholm University, August 1997b. An earlier version was published in August 1996 as NBER Working Paper 5719.

Taylor, John B. "The Inflation/ Output Variability Tradeoff Revisited," in Goals, Guidelines, and Constraints Facing Monetary Policymakers, Jeffrey C. Fuhrer, ed., The Federal Reserve Bank of Boston Conference Series 38 (1994), pp. 21-38.

"Estimation and Control of a Macroeconomic Model with Rational Expectations," Econometrica 47 (September 1979), pp. 1267-86. 


\section{APPENDIX: SOLUTION OF THE CENTRAL BANK'S OPTIMIZATION PROBLEM}

Since the central bank's objective under either the inflation targeting or price-level-targeting regime is quadratic and its constraints are linear, it is possible to guess that linear-decision rules solve the bank's optimization problem. We show that substituting the conjectured linear rules into the first-order conditions for the bank's optimization problem and equating coefficients will yield the decision rules described in the text. We treat inflation expectations as equilibrium variables are treated in a dynamic general equilibrium model. That is, we suppose that the bank bases its decisions at time $t$ solely on the state variables $\mathrm{y}_{\mathrm{t}-1}$ and $\varepsilon_{\mathrm{t}}$ while inflation expectations are left to be determined by a rational expectations condition.

Consider first the inflation-targeting regime. We form the bank's Lagrangian as:

$$
\mathrm{E}_{0}\left\{\sum_{\mathrm{t}=0}^{\infty} \beta^{\mathrm{t}}\left[\begin{array}{l}
\lambda \mathrm{y}_{\mathrm{t}}^{2}+\left(\pi_{\mathrm{t}}-\pi^{*}\right)^{2} \\
-\mu_{\mathrm{t}}\left(\begin{array}{l}
\mathrm{y}_{\mathrm{t}}-\rho \mathrm{y}_{\mathrm{t}-1} \\
-\alpha\left(\pi_{\mathrm{t}}-\pi_{\mathrm{t}}^{\mathrm{e}}\right)-\varepsilon_{\mathrm{t}}
\end{array}\right)
\end{array}\right]\right),
$$

where the $\mu_{\mathrm{t}}$ 's are a sequence of random multipliers. The bank's first-order conditions take the form:

$$
2 \lambda \mathrm{y}_{\mathrm{t}}-\mu_{\mathrm{t}}+\beta \rho \mathrm{E}_{\mathrm{t}} \mu_{\mathrm{t}+1}=0,
$$

when taken with respect to the sequence of $y_{t} s$, and the form:

$$
2\left(\pi_{\mathrm{t}}-\pi^{*}\right)+\alpha \mu_{\mathrm{t}}=0,
$$

when taken with respect to the sequence of $\pi_{\mathrm{t}} \mathrm{s}$. Eliminating the multipliers from these expressions gives the following Euler equation:

$$
\begin{aligned}
\lambda \mathrm{y}_{\mathrm{t}} & +\frac{1}{\alpha}\left(\pi_{\mathrm{t}}-\pi^{*}\right) \\
& -\frac{\beta \rho_{\mathrm{E}}}{\alpha} \mathrm{E}_{\mathrm{t}}\left(\pi_{\mathrm{t}+1}-\pi^{*}\right)=0 .
\end{aligned}
$$

We now posit a linear decision rule for inflation of the form:

$$
\pi_{\mathrm{t}}=\mathrm{A}_{1}+\mathrm{A}_{2} \mathrm{y}_{\mathrm{t}-1}+\mathrm{A}_{3} \varepsilon_{\mathrm{t}}
$$

If expectations formed at time t- 1 are rational then:

$$
\pi_{\mathrm{t}}^{\mathrm{e}}=\mathrm{A}_{1}+\mathrm{A}_{2} \mathrm{y}_{\mathrm{t}-1} .
$$

Hence, the constraint imposed by the aggregate supply relation (Equation 2 in the article) yields a decision rule for $y_{t}$ directly of the form:

$$
\mathrm{y}_{\mathrm{t}}=\rho \mathrm{y}_{\mathrm{t}-1}+\left(\alpha \mathrm{A}_{3}+1\right) \varepsilon_{\mathrm{t}}
$$

Note that decision rules are invariant so that $\pi_{\mathrm{t}+1}$ can be determined by iterating on the rule for $\pi_{\mathrm{t}}$ to yield the following expression:

$$
\begin{aligned}
& \pi_{\mathrm{t}+1}=\mathrm{A}_{1}+\mathrm{A}_{2} \mathrm{y}_{\mathrm{t}}+\mathrm{A}_{3} \varepsilon_{\mathrm{t}}=\mathrm{A}_{1} \\
& +\mathrm{A}_{2}\left(\rho \mathrm{y}_{\mathrm{t}-1}+\left(\alpha \mathrm{A}_{3}+1\right) \varepsilon_{\mathrm{t}}\right)+\mathrm{A}_{3} \varepsilon_{\mathrm{t}+1} .
\end{aligned}
$$

Substituting Equations A5, A7, and A8 into the Euler Equation A4 above, taking expectations, and equating constant terms and coefficients on the states yields values for $A_{1}, A_{2}$, and $A_{3}$ in terms of parameters of the model.

Determining the bank's decision rules in the case of a price-level-targeting regime proceeds in a similar fashion. The only difference is the bank's price-level target changes over time, and hence $p_{t}^{*}$ must enter as a state variable in the bank's decision rules. Since this target evolves in a deterministic manner as $\mathrm{p}_{\mathrm{t}}^{*}=\mathrm{p}_{\mathrm{t}-1}{ }^{*}+\pi^{*}$, however, it is still 


\section{REVIEW}

J ANUARY / FEBRUARY 1999

possible to postulate a decision rule of the form $p_{t}=A_{1}+A_{2} p_{t}^{*}+A_{3} y_{t-1}+A_{4} \varepsilon_{t}$, and iterate on it to calculate $p_{t+1}$ in terms of time t states. After substituting the resultant linear rules into the bank's Euler equation and equating coefficients, we obtain the decision rule for price-level targeting given in the text. 
JANUARY/ FEBRUARY 1999

FEDERAL RESERVE BANK OF ST. LOUIS 